\title{
Snubbing and Bundling Effects on Multiple Crack Spacing of Discontinuous Random Fiber-Reinforced Brittle Matrix Composites
}

\author{
Hwai-Chung $\mathrm{Wu}^{\star}$ and Victor $\mathrm{C}$. Li
}

Advanced Civil Engineering Materials Research Laboratory, Department of Civil and Environmental Engineering. University of Michigan, Ann Arbor, Michigan 48109-2125

\begin{abstract}
Multiple cracking due to pseudo strain-hardening of fiberreinforced brittle matrix composites contributes significantly to enhanced composite strain capacity as well as toughness. This unique phenomenon is true for both continuous aligned and discontinuous random fiber composites. Theoretical formulation of multiple crack spacing is reviewed in this paper. In particular, a snubbing effect of fiber pullout and a bundling effect of fiber strands on crack spacing are discussed. Taking account of these effects, expressed via the snubbing coefficient, $f$, and effective bond strength, $\tau_{\text {eff }}$, a better spacing prediction has been obtained for a discontinuous random glass-strand-reinforced cement composite.
\end{abstract}

\section{Introduction}

$\mathbf{F}$ IBER reinforcement is an effective way of improving strength as well as toughness of brittle materials. This is generally attributed to microcrack suppression and fiber pullout. In addition, adequate fiber reinforcement can offer much enhanced composite strain capacity due to pseudo strainhardening. ${ }^{1,2}$ This means that, beyond the limit of proportionality, the composite behaves more like ductile metals than like brittle materials. The classical work by Aveston $e t a l{ }^{3}$ and later extensions by Marshall et al. ${ }^{4,5}$ laid the foundations for micromechanical modeling of the pseudo strain-hardening phenomenon for continuous aligned fiber-reinforced brittle matrix composites (designated as CA composites). Further extension to discontinuous random fiber-reinforced composites (designated as DR composites), which possess low production cost and processing ease, is proposed by Li and Leung ${ }^{6}$ and Li and Wu. ${ }^{2}$ These models provide linkage between micromechanical parameters such as fiber, matrix, and interface properties, and the composite properties.

The pseudo strain-hardening process is made possible by the stress transfer capability of bridging fibers. This phenomenon is associated with the multiple cracking of the brittle matrix. When the composite is loaded up to its first cracking strength under uniaxial tensile loading, a first macroscopic crack is formed in the composite. The composite load will then be shared by the bridging fibers. These fibers then transfer the load via their interface back into the matrix. If enough load is transferred, the matrix may crack again and the process repeats until the matrix is broken by a series of subparallel cracks of approximately equal crack spacing. ${ }^{2}$

D. B. Marshall-contributing editor

\section{Theory}

\section{(l) Snubbing Effect}

The physical interpretation of multiple cracking mentioned above is applicable to both CA and DR composites. Aveston et al ${ }^{3}$ have determined the multiple crack spacing of CA composites between $x^{\prime}$ and $2 x^{\prime}$, and $x^{\prime}$ is defined as

$$
x^{\prime}=\frac{E_{\mathrm{m}} V_{\mathrm{m}}}{V_{\mathrm{f}}} \frac{\varepsilon_{\mathrm{mu}} r_{\mathrm{f}}}{2 \tau_{\text {eff }}}=\frac{V_{\mathrm{m}}}{V_{\mathrm{f}}} \frac{\sigma_{\mathrm{mu}} r_{\mathrm{f}}}{2 \tau_{\text {eff }}}
$$

where $E_{\mathrm{m}}$ is the matrix modulus, $V_{\mathrm{f}}, V_{\mathrm{m}}$ are the volume fraction of fiber and matrix, respectively, $\varepsilon_{\mathrm{mu}}, \sigma_{\mathrm{mu}}$ are the matrix failure strain/stress, $r_{\mathrm{f}}$ is the fiber radius, and $\tau_{\mathrm{eff}}$ is the effective interfacial bond strength.

In DR composites, Aveston et al. ${ }^{7}$ considered the stress transfer via inclined short fibers to the cracked plane for 2-D composites, which leads to

$$
x_{2}^{\prime}=\frac{L_{\mathrm{f}}-\sqrt{L_{\mathrm{f}}^{2}-2 \pi L_{\mathrm{f}} x^{\prime}}}{2}
$$

where $L_{\mathrm{f}}$ is the discontinuous fiber length; $\mathrm{x}^{\prime}$ is defined in Eq. (1).

As shown in Eq. (2), $x_{2}^{\prime}$ (subscript 2 here indicates 2-D randomness in fiber orientation) is less than $L_{\mathrm{f}} / 2$, which is the average embedment length in either side of the cracked plane. In other words, bridging fibers should be long enough to transfer stress back into the matrix for subsequent matrix cracking. In deriving Eq. (2), the inclined fibers are treated as bending over a frictionless pulley at their exit points from the cracked plane. ${ }^{7}$ The pulley serves only to change the loading direction. More recently, a generalized formulation of load transfer by bridging fibers accounting for general randomness (2-D or 3-D) of fiber orientation and location has been presented. ${ }^{8}$ In the special case of 2-D uniform random fiber distribution with the frictionless pulley assumption, this formulation leads to the crack spacing given in Eq. (2) (see Eq. (4) below with $f=0$ ).

Beyond the frictionless pulley assumption, Li et al. ${ }^{9}$ reported a snubbing effect which results in better agreement with experimental data of inclined fiber pullout tests. This can be envisioned as a flexible rope passing over a frictional pulley (see Fig. 1). The snubbing effect amplifies the bridging force due to fiber/matrix snubbing when a fiber is pulled out at an angle to the loading axis, expressed via the snubbing coefficient, $f$, where $f$ is found to be 0.994 for nylon fiber and 0.702 for polypropylene fiber. ${ }^{9}$ When the snubbing effect is inactive, $f$ equals zero and coincides with the frictionless pulley assumption.

In considering the snubbing effect, the multiple crack spacing of discontinuous random fiber-reinforced composites can be derived: ${ }^{10}$

$$
x_{1}^{\prime}=\frac{L_{\mathrm{f}}-\sqrt{L_{\mathrm{f}}^{2}-2 \pi L_{\mathrm{f}} \alpha x^{\prime}}}{2} \text { for 1-D }
$$

where

$$
\alpha=\frac{2}{\pi}
$$




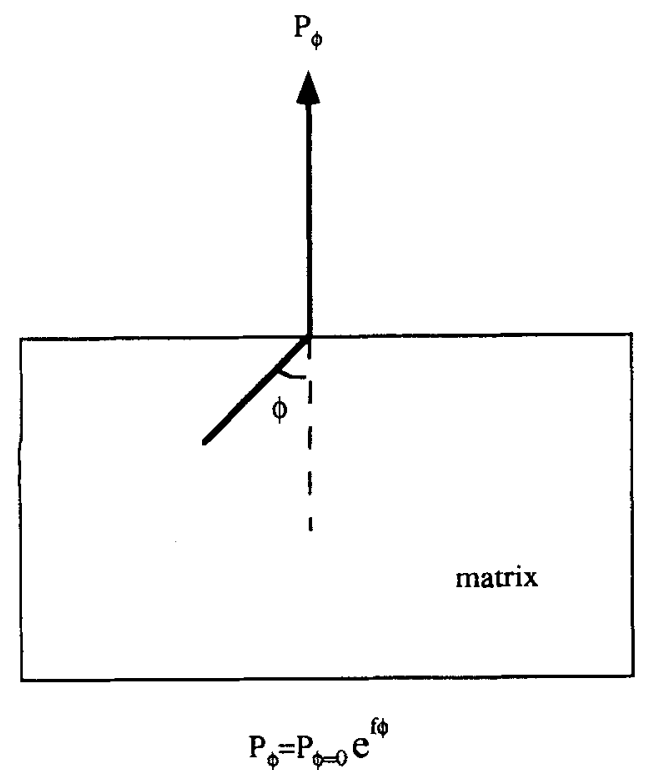

Fig. 1. Fiber pullout at an angle from the matrix, showing snubbing effect.

$$
x_{2}^{\prime}=\frac{L_{\mathrm{f}}-\sqrt{L_{\mathrm{f}}^{2}-2 \pi L_{\mathrm{f}} \kappa x^{\prime}}}{2} \text { for 2-D }
$$

where

$$
\kappa=\frac{1+f^{2}}{e^{\pi f / 2}-f}
$$

and

$x_{3}^{\prime}=\frac{L_{\mathrm{f}}-\sqrt{L_{\mathrm{f}}^{2}-2 \pi L_{\mathrm{f}} \lambda x^{\prime}}}{2} \quad$ for $3-\mathrm{D}$

where

$$
\begin{aligned}
& \lambda=\frac{2}{\pi} \frac{4+f^{2}}{e^{\pi f / 2}+1}=\frac{4}{\pi g} \\
& g \text { is snubbing factor }=2 \frac{e^{\pi j i 2}+1}{4+f^{2}}
\end{aligned}
$$

The dependency of snubbing coefficient on the crack spacing reduction parameters is plotted in Fig. 2 for I-D, 2-D, and 3-D fiber randomness. It is most efficient for stress transfer when fibers are aligned with the loading direction. Therefore, as suggested in Fig. 2 and Eqs. (3)-(5), the crack spacing of 1-D, 2-D and 3-D fiber composites is in increasing order. However, the

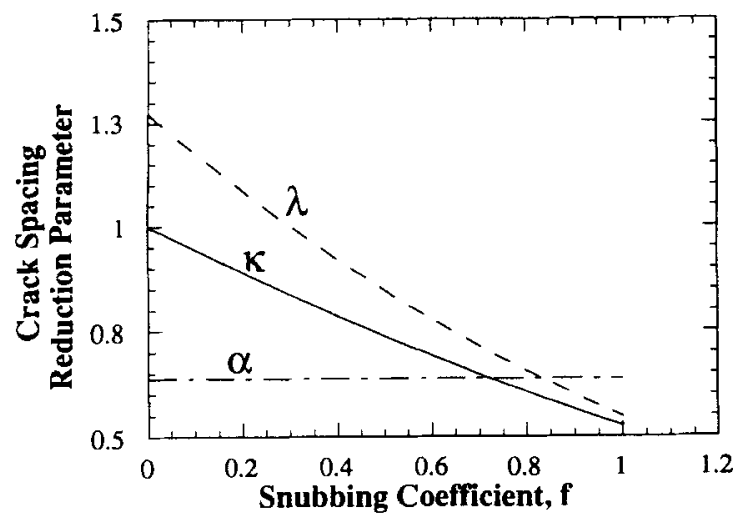

Fig. 2. Effect of snubbing coefficient on crack spacing reduction for 1-D $(\alpha), 2-D(\kappa)$, and 3-D $(\lambda)$ fiber composites (see Eqs. 3-5).

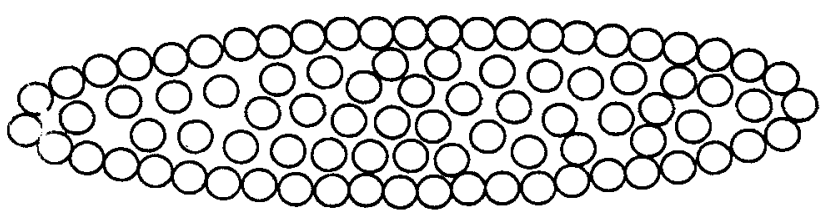

(A)

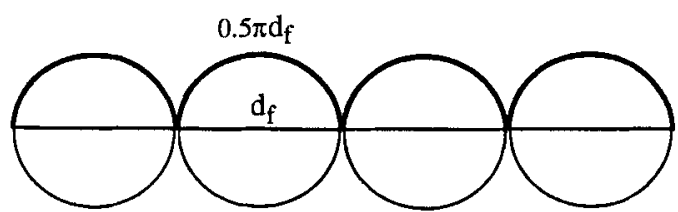

(B)

Fig. 3. (A) Schematic cross section of a glass fiber strand. (B) Surface roughness along circumference in $(A)$.

snubbing effect is in favor of short crack spacing. In 1-D composites, the snubbing effect does not exist. Hence, for 2-D or 3-D composites with high snubbing coefficients, the snubbing effect on crack spacing can dominate over the fiber orientation effect and result in smaller crack spacing than 1-D composites.

\section{(2) Bundling Effect}

In practice, many reinforcing fibers such as $\mathrm{SiC}$ or glass are frequently used in discontinuous chopped lengths, normally in bundles or strands containing 100-200 individual filaments. The shape of the cross section of such fiber strands in the composites is commonly observed as an ellipse with varied ellipticity (Fig. 3(A))..$^{11,12}$ Bond strength, $\tau$, is typically measured on a single-fiber basis. Hence, an effective $\tau$ should be employed when fiber bundles instead of discrete fibers are used in load transfer models. $\tau_{\text {eff }}$ may be determined from a geometric consideration as follows.

For a fiber strand of unit thickness, the effective bond strength, $\tau_{\text {eff }}$, can be related to the bond strength of a single fiber, $\tau$, as ${ }^{9}$

$$
\tau_{\text {eff }}=\tau \frac{A_{\text {exposed }}}{A_{\text {total }}}
$$

where $A_{\text {exposed }}$ is the exposed surface area of an elliptical fiber strand along its circumference, and $A_{\text {total }}$ is the total fiber surface area per strand, expressed as

$$
A_{\text {total }}=N\left(\pi d_{\mathrm{f}}\right)
$$

and $N$ is the total numbers of fibers per strand, and $d_{\mathrm{f}}$ is the fiber diameter.

Since the exposed surface of the fiber bundle is approximated as semicircular cylinders superimposed on an ellipse (see Fig.

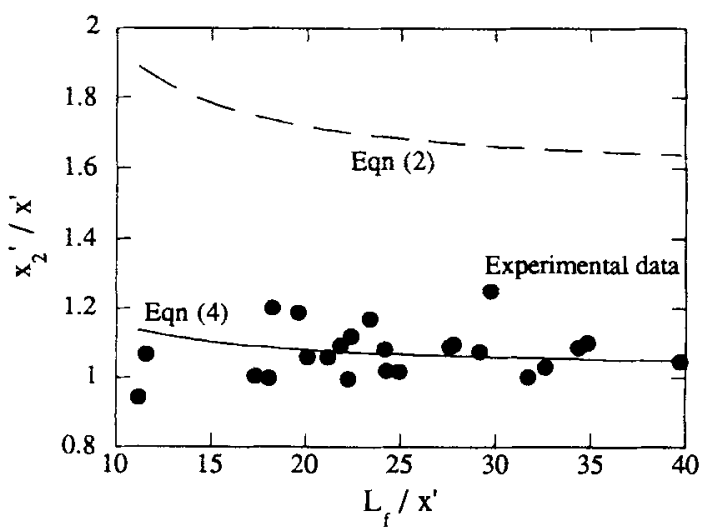

Fig. 4. Normalized crack spacing versus fiber length of glass-strandreinforced cement (after Oakley and Proctor ${ }^{11}$ ). 
$3(B))$, the ratio of the circumference of a semicircle to its diameter represents the bundle surface roughness. Hence

$$
A_{\text {exposed }}=\left(2 \pi \sqrt{\frac{a^{2}+b^{2}}{2}}\right) \frac{0.5 \pi d_{f}}{d_{f}}
$$

where the value inside the parentheses is the circumference of an ellipse with axes $a$ and $b$.

Therefore, using Eqs. (7) and (8) in Eq. (6),

$$
\tau_{\text {eff }}=\tau \frac{\sqrt{2\left(a^{2}+b^{2}\right)}}{N d_{\mathrm{f}}}(0.5 \pi)
$$

Equation (9) should be used together with Eqs. (1)-(5) to predict crack spacing whenever fiber bundles of an elliptical geometry are utilized in the composites.

As an example, per Oakley and Proctor, ${ }^{11}$ the glass used in their reinforced cement composites was in the form of $38-\mathrm{mm}$ long chopped strands, and the strands consisted of 200 fibers, each $12.5 \mu \mathrm{m}$ in diameter, in a flat bundle held together by a size coating. The strand cross section may be approximated as an ellipse with long axis $a$ and short axis $b$ (see Fig. 3(A), also Oakley and Proctor ${ }^{\prime \prime}$ ), where $a=0.325 \mathrm{~mm}$ and $b=0.055$ $\mathrm{mm}$ according to Oakley and Proctor from their experimental measurements of the cross-section area of the glass strands in the cement composites. When these values are used in Eq. (9), $\tau_{\text {eff }}$ is found to be $0.29 \tau$.

\section{Results}

The available data on the multiple crack spacing of discontinuous random fiber composites are very limited in the literature. Oakley and Proctor ${ }^{11}$ reported a series of tensile tests on glass fiber (2-D orientation) reinforced cement composites, including crack spacing measurements. Their results are reproduced in Fig. 4 , together with the predictions of multiple crack spacing obtained from Eqs. (2) and (4) where $\tau_{\text {eff }}(\mathrm{Eq} .(9))$ is employed in both cases. In Eq. (9), $\tau$ ranging from 0.2 to $1.6 \mathrm{MPa}$ are used. These values are experimentally measured for each individual composite. ${ }^{11}$ In Eq. (4), since there is no experimental data of snubbing coefficient for glass fiber in cement, $f=0.7$ is assumed. Limited data on nylon, polypropylene, and steel fibers show $f$ varying between 0.5 and 1 . The spacing and fiber length are all normalized by $x^{\prime}$, as defined in Eq. (1). Good agreements are found when the snubbing effect is accounted for in terms of the snubbing coefficient, $f$; however, the exact magnitude requires further investigation. The frictionless pulley theory, Eq. (2), as proposed by Aveston et al. ${ }^{3.7}$ gives significant overestimation.

\section{Conclusions}

Multiple crack spacing of discontinuous random fiberstrand-reinforced brittle matrix composites is dependent on the snubbing effect, which amplifies the bridging force due to fiber/matrix snubbing, and on the bundling effect, which reduces bond strength and bridging force. Good agreements between theoretical predictions and experimental data of a glass-strand-reinforced cement have been found when these two effects are considered

\section{References}

'V. C. Li and H. C. Wu, "Micromechanics Based Design for Pseudo StrainHardening in Cementitious Composites"; pp. 740-43 in Proceedings of the ASCE 9th Engineering Mechanics Conference, College Station, TX, May 24 27, 1992. American Society of Civil Engineers, New York, 1992

${ }^{2}$ V. C. Li and H. C. Wu, "Conditions for Pseudo Strain-Hardening in Fiber Reinforced Brittle Matrix Composites," Appl. Mech. Rev., 45 [8] 390-98 (1992)

J. Aveston. G. A. Cooper, and A. Kelly, "Single and Multiple Fracture"; pp. 15-24, in the Properties of Fiber Composites, conference proceedings, National Physical Laboratory. IPC Science and Technology Press Ltd. . Guildford, Surrey, U.K., 1971.

${ }^{4}$ D. B. Marshall, B. N. Cox, and A. G. Evans, "The Mechanies of Matrix Cracking in Brittle-Matrix Fiber Composites," Acta Metall., 33 [11] 2013-21 (1985).

5D. B. Marshall and B. N. Cox, "Tensile Fracture of Brittle Matrix Composites: Influence of Fiber Strength," Acta Metall. 35 [11]2607-19 (1987).

"V. C. Li and C. K. Leung, "Theory of Steady State and Multiple Cracking of Random Discontinuous Fiber Reinforced Brittle Matrix Composites," J. Eng. Mech. Div, Am. Soc. Civ. Eng., 118, [1 1] 2246-64 (1992).

7J. Aveston, R. A. Mercer, and J. M. Sillwood, "Fiber Reinforced CementsScientific Foundations for Specifications"; pp. 93-103 in Composites-Stan dards, Testing and Design. conference proceedings, National Physical Labora tory. IPC Science and Technology Press Ltd., Guildford, Surrey, U. K., 1974.

${ }^{8}$ V. C. Li, Y. Wang, and S. Backer, "A Micromechanical Model of TensionSoftening and Bridging Toughening of Short Random Fiber Reinforced Brittle Matrix Composites," f. Mech. Phys. Solids, 39 [5] 607-25 (1991)

${ }^{9} \mathrm{~V}$. C. Li, Y. Wang, and S. Backer, "Effect of Inclining Angle. Bundling, and Surface Treatment on Synthetic Fiber Pull-out from a Cement Matrix," Composites, 21 [2] 132-40 (1990).

"V. C. Li and H. C. Wu, "Properties of Pseudo Strain-Hardening in Short Random Fiber Reinforced Cementitious Composites"; unpublished work

"D. R. Oakley and B. A. Proctor, "Tensile Stress-Strain Behavior of Glass Fiber Reinforced Cement Composites"; pp. 347-59 in Rilem Symposium Fiber Reinforced Cement and Concrete. Construction Press, Harlow, Essex, U.K., 1975.

${ }^{12} \mathrm{~N}$. McN. Alford and J. D. Birchall, "Fiber Toughening of MDF Cement," J. Mater. Sci., 20, 37-45 (1985). 